\title{
Type 2 diabetes mellitus might be a risk factor for mild cognitive impairment progressing to Alzheimer's disease
}

This article was published in the following Dove Press journal:

Neuropsychiatric Disease and Treatment

29 September 2016

Number of times this article has been viewed

\author{
Wei $\mathrm{Li}^{1,2}$ \\ Tao Wang ${ }^{1,2}$ \\ Shifu Xiao ${ }^{1,2}$ \\ 'Alzheimer's Disease and Related \\ Disorders Center, ${ }^{2}$ Department of \\ Geriatric Psychiatry, Shanghai Mental \\ Health Center, Shanghai Jiaotong \\ University School of Medicine, \\ Shanghai, People's Republic of China
}

Correspondence: Shifu Xiao Alzheimer's Disease and Related Disorders Center, Shanghai Jiaotong University School of Medicine, No. 600 South Wanping Road, Xuhui Distinct, Shanghai 200030, China

Tel +86 2l 64387250

Email xiaoshifu@msn.com
Background: Mild cognitive impairment (MCI) is the prodromal stage of Alzheimer's disease (AD), so identification of the related risk factors can be helpful. Although the association between type 2 diabetes mellitus (T2DM) and these modest changes in cognition is well established, whether T2DM will promote the transformation of MCI into AD is not a unified conclusion.

Objective: This study aims to explore the relationship between T2DM and MCI in the elderly population living in the community in Shanghai, People's Republic of China.

Methods: A total of 197 participants were included in the study. They were screened for T2DM, hyperlipidemia, traumatic brain injury, and family history of dementia. The Mini-Mental State Examination and the Montreal Cognitive Assessment were used to assess cognitive function. The diagnosis of AD was made according to Diagnostic and Statistical Manual of Mental Disorders, Fourth Edition, whereas the diagnosis of MCI was made according to Petersen's criteria. Then, we investigated the relation between T2DM and MCI.

Results: A total of 82 (41.6\%) participants had no cognitive impairment, $82(41.6 \%)$ participants had MCI, and 33 (16.8\%) participants had AD. Multivariate logistic regression models demonstrated that $\mathrm{T} 2 \mathrm{DM}$ was a risk factor for $\mathrm{AD}$ (odds ratio $=49.723$, 95\% CI $=21.173-111.987$ ).

Conclusion: T2DM might be a risk factor for MCI progressing into AD.

Keywords: T2DM, AD, MCI, risk factor

\section{Introduction}

Alzheimer's disease (AD) is a progressive neurodegenerative disorder and the most common form of dementia among the population aged $>65$ years. ${ }^{1}$ It is characterized by extracellular amyloid plaques and neurofibrillary tangles. ${ }^{2}$ Mild cognitive impairment (MCI) is often considered to be a transitional phase between healthy cognitive aging and $\mathrm{AD} .{ }^{3} \mathrm{Up}$ to $60 \%$ of MCI patients will develop $\mathrm{AD}$ within a 10 -year period, but many people can remain cognitively stable or regain normal cognitive function. ${ }^{4}$ There are many factors that affect the progress of MCI, for example, sex difference. 5 Type 2 diabetes mellitus (T2DM) might also be a potential risk for MCI progressing into $\mathrm{AD}$, by inducing vascular dysfunction and oxidative and inflammatory stress. ${ }^{6}$ Many cognitive functions, such as learning and memory, mental flexibility, and mental speed, have also been proved to be impaired in patients with T2DM. ${ }^{7}$ Some epidemiological studies demonstrated that T2DM was a risk factor for developing cognitive impairment and dementia, including AD. ${ }^{8,9}$ Also, a prospective longitudinal study conducted in the southeastern region of Singapore showed that T2DM was associated with an increased incidence of MCI and progression to dementia. ${ }^{10}$ However, Leibson et $\mathrm{al}^{11}$ 
reported that $\mathrm{T} 2 \mathrm{DM}$ can increase the risk of $\mathrm{AD}$ in male patients, whereas Atiea et al believed that T2DM will not affect the prognosis of MCI. Some previous studies even reported that T2DM cases with MCI have less neurofibrillary tangles and fewer neuritic plaques in both cerebral cortex and hippocampal region. ${ }^{12}$ And some antidiabetic medications, such as the glucagon-like peptide-1 receptor agonists, might inhibit the accumulation of A $\beta$ protein. ${ }^{13}$ Since there are no definitive conclusions (based on the published data) about the relation between T2DM and MCI in Chinese population, we designed this study to explore the association of MCI with T2DM and the potential risk factors for AD in the People's Republic of China.

\section{Methods}

\section{Study participants}

This cross-sectional, population-based study was carried out between June 1 and August 31, 2011. All the participants were recruited from urban sites in the North XinJing district of Shanghai, People's Republic of China. The inclusion criteria were as follows: 1) 55 years and older; 2) living in Shanghai for at least 2 years; 3 ) no evidence of serious physical illness or serious mental illness, such as schizophrenia and mental retardation; 4) primary school and higher education; and 5) agreed to participate in the study. Exclusion criteria were as follows: 1) acute stress state, for example, acute medical disorders; 2) serious physical illness or serious mental illness; 3) illiteracy; and 4) the participants or the guardians refused to participate in the study. Finally, 525 elderly participants entered this study.

Ethical approval was obtained from Shanghai Mental Health Centre, and all the participants had signed an informed consent before the study was initiated.

\section{Study design and measurements}

This study consisted of two steps: step 1 for screening all the eligible participants and step 2 for the confirmation of the suspected cases of MCI and AD.

In step 1, all the 525 participants completed a face-to-face interview with a standardized questionnaire. The interview was conducted by trained graduate students, and it included general demographics (eg, age, sex, education, occupation, and living arrangements), living habits (eg, smoking, drinking, and tea), and history of diseases (eg, T2DM, hyperlipidemia, traumatic brain injury, and family history of dementia). Then, the Mini-Mental State Examination (MMSE) and the Montreal Cognitive Assessment (MoCA) were used to screen for cognitive impairment. The MMSE is a good cognitive assessment tool, which has been widely used in both clinical and research settings. It can be used to screen patients for cognitive impairment, track changes in cognitive functioning over time, and access the effects of therapeutic agents on cognitive function. ${ }^{14} \mathrm{MMSE}$ has a good sensitivity and specificity for the detection of dementia, but for the detection of nondementia cognitive impairment, its sensitivity is only $20 \%-60 \% .{ }^{15}$ In order to correct MMSE deficiencies, the MoCA has been introduced into clinical practice. MoCA is a 10-20-minute screening test designed for assisting clinicians in detecting early or minor cognitive impairment. It covers many major cognitive domains, including episodic memory, language, attention, orientation, visuospatial ability, and executive functions. ${ }^{16}$ Similar to MMSE, MoCA is also very brief and easy to administer. However, it contains some more challenging tests such as executive function, higher-level language, and complex visuospatial processing, which are considered to be able to detect MCI with less ceiling effect. ${ }^{17}$ The scores of the MMSE $(\leq 27)$ and MoCA $(<26)$ were taken together to evaluate cognitive impairment. ${ }^{18}$

After cognitive testing, an extensive medical examination was conducted by trained and qualified medical clinicians which led to a consensus diagnosis of MCI and AD. MCI was diagnosed according to the revised Petersen's diagnostic algorithm, ${ }^{19}$ and AD was diagnosed according to the Diagnostic and Statistical Manual of Mental Disorders, fourth edition. In order to exclude vascular dementia (VD) and other diseases that might affect cognition, we added magnetic resonance imaging and blood biochemical tests. At the same time, we also applied the geriatric depression scale $^{20}$ to exclude depression.

\section{Data analysis}

Continuous variables were expressed as mean and SD, and categorical variables were expressed as frequencies (\%). One-way analysis of variance (ANOVA) was used to compare the differences among the no cognitive impairment (NCI) group, MCI group, and AD group. Related factors of cognition were analyzed using multifactor logistic regression models. Two-tailed tests were used at a significance level of $P<0.05$ for all analyses. The data were analyzed using SPSS 22.0 (IBM Corporation, Armonk, NY, USA).

\section{Results}

Using a combination of cognitive tests, the clinical investigations, and laboratory testing, three groups were established consisting of NCI $(n=82), \operatorname{MCI}(n=82)$, and AD $(n=33)$. (Other missing data included: four people who could not be diagnosed, eight people with VD, two people with 
frontotemporal dementia, three people with mixed dementia, 27 people with depression, one with syphilis, one with type 1 diabetes mellitus, while others could not be determined if there was a combination of T2DM).

\section{Demographic characteristics}

Table 1 shows the characteristics of the 197 participants. The average age was $74.2 \pm 10.7$ years (range $55-100$ years): $18.7 \%$ were in the 55-59-year group, $13.7 \%$ were in the 60-64-year group, $10.7 \%$ were in the 65-69-year group, $11.2 \%$ were in the $70-74$-year group, $21.3 \%$ were in the 75-79-year group, $24.4 \%$ were in the 80-100-year group; 69 (35\%) were males; 65 (33\%) were engage in mental work; $167(84.8 \%)$ had lived in the city for a long time, $13(6.6 \%)$

Table I Demographic characteristics of the study population

\begin{tabular}{|c|c|c|}
\hline Characteristics & $\mathbf{N}$ & $\%$ \\
\hline \multicolumn{3}{|l|}{ Age group (years) } \\
\hline $55-59$ & 37 & 18.7 \\
\hline $60-64$ & 27 & 13.7 \\
\hline $65-69$ & 21 & 10.7 \\
\hline $70-74$ & 22 & 11.2 \\
\hline $75-79$ & 42 & 21.3 \\
\hline$\geq 80$ & 48 & 24.4 \\
\hline \multicolumn{3}{|l|}{ Sex } \\
\hline Male & 69 & 35 \\
\hline Female & 128 & 65 \\
\hline \multicolumn{3}{|c|}{ Professional nature } \\
\hline Mental labor & 65 & 33 \\
\hline Manual labor & 132 & 67 \\
\hline \multicolumn{3}{|c|}{ Long-term residence } \\
\hline City & 167 & 84.8 \\
\hline Town & 13 & 6.6 \\
\hline Village & 17 & 8.6 \\
\hline \multicolumn{3}{|l|}{ Smoking } \\
\hline Yes & 37 & 18.8 \\
\hline No & 160 & 81.2 \\
\hline \multicolumn{3}{|l|}{ Drinking alcohol } \\
\hline Yes & 27 & 13.7 \\
\hline No & 170 & 86.3 \\
\hline \multicolumn{3}{|l|}{ Drinking tea } \\
\hline Yes & 75 & 38.1 \\
\hline No & 122 & 61.9 \\
\hline \multicolumn{3}{|l|}{ Diabetes } \\
\hline Yes & 33 & 16.8 \\
\hline No & 164 & 83.2 \\
\hline \multicolumn{3}{|l|}{ Hyperlipidemia } \\
\hline Yes & 41 & 20.8 \\
\hline No & 156 & 79.2 \\
\hline \multicolumn{3}{|c|}{ Family history of dementia } \\
\hline Yes & 4 & 2 \\
\hline No & 193 & 98 \\
\hline \multicolumn{3}{|c|}{ Traumatic brain injury } \\
\hline Yes & 14 & 7.1 \\
\hline No & 183 & 92.9 \\
\hline
\end{tabular}

had lived in the town for a long time, and $17(8.6 \%)$ had lived in the villages for a long time; 37 (18.8\%) had a smoking habit; 27 (13.7\%) had a drinking habit; 75 (38.1\%) had a tea drinking habit; 33 (16.8\%) with T2DM; 41 (20.8\%) with hyperlipidemia; four $(2 \%)$ had a history of dementia; and $14(7.1 \%)$ experienced traumatic brain injury.

\section{Differences among the three groups $(\mathrm{NCl}, \mathrm{MCl}$, and $\mathrm{AD}$ ) by one-way ANOVA}

Table 2 shows the differences among the three groups (NCI, $\mathrm{MCI}$, and $\mathrm{AD}$ ) in categorical variables using the one-way ANOVA. Professional nature (engaged in mental or physical labor), long-term residence (city, town, or village), drinking tea (yes or no), T2DM (yes or no), hyperlipidemia (yes or no), and traumatic brain injury (yes or no) were statistically significantly different among the three groups $(P<0.05)$, and their $P$-values were $0.000,0.003,0.000,0.032,0.001$, and 0.041 , respectively.

Table 3 shows the differences among the three groups in continuous variables. Age, education, the scores of MMSE and MoCA, height, and weight were statistically significantly different among the three groups $(P<0.05)$, and their $P$-values were $0.000,0.000,0.000,0.000,0.034$, and 0.003 , respectively.

Table 4 shows the detailed disease information in the three groups, T2DM (yes or no), hyperlipidemia (yes or no), and traumatic brain injury (yes or no) and they were statistically significantly different among the three groups $(P<0.05)$, and their $P$-values were $0.032,0.001$, and 0.041 , respectively.

Table 5 shows the detailed disease information between MCI group and AD group, and hyperlipidemia (yes or no) was statistically significantly $(P=0.001)$ different between the two groups.

\section{Possible factors associated with AD by multivariate logistic regression models}

Based on previous statistical conclusions and clinical experience, professional nature (engaged in mental or physical labor), long-term residence (city, town, or village), drinking tea (yes or no), T2DM (yes or no), hyperlipidemia (yes or no), traumatic brain injury (yes or no), age, sex, education, the scores of MMSE and MoCA, height, and weight were included in the multivariate logistic regression models. We found that T2DM (odds ratio $=49.723,95 \% \mathrm{CI}=21.173-$ 111.987) might be a risk factor for $\mathrm{AD}$ (Table 6; comparison between the $\mathrm{AD}$ group and $\mathrm{MCI}$ group), while there was no related factor found between the $\mathrm{AD}$ group and $\mathrm{NCI}$ group. 
Table 2 Univariate analysis of cognitive impairment (categorical variables)

\begin{tabular}{|c|c|c|c|c|c|}
\hline Group & Sum of squares & $d f$ & Mean square & $\boldsymbol{F}$ & $P$-value \\
\hline Sex: male or female & 0.889 & 2 & 0.445 & 1.963 & 0.143 \\
\hline Professional nature: mental or manual & 4.300 & 2 & 2.150 & 10.766 & 0.000 \\
\hline Long-term residence: city, town, or village & 4.142 & 2 & $2.07 \mid$ & 6.069 & 0.003 \\
\hline Smoking: yes or no & 0.505 & 2 & 0.253 & 1.659 & 0.193 \\
\hline Drinking alcohol: yes or no & 0.080 & 2 & 0.040 & 0.353 & 0.703 \\
\hline Drinking tea: yes or no & 3.574 & 2 & 1.787 & 8.118 & 0.000 \\
\hline Diabetes: yes or no & 1.503 & 2 & 0.527 & 3.514 & 0.032 \\
\hline Hyperlipidemia: yes or no & 5.310 & 2 & 2.655 & 13.272 & 0.001 \\
\hline Family history of dementia: yes or no & 0.875 & 2 & 0.438 & 2.451 & 0.653 \\
\hline Traumatic brain injury: yes or no & 0.420 & 2 & 0.210 & 3.235 & $0.04 I$ \\
\hline
\end{tabular}

Abbreviation: $d f$, degrees of freedom.

Table 3 Univariate analysis of cognitive impairment (continuous variables)

\begin{tabular}{|c|c|c|c|c|c|}
\hline Group & Normal & $\mathrm{MCl}$ & Dementia & $\boldsymbol{F}$ & $P$-value \\
\hline Age (years), mean $\pm S D$ & $68.48 \pm 11.546$ & $71.35 \pm 10.197$ & $79.76 \pm 5.990$ & 14.292 & 0.000 \\
\hline Education (years), mean \pm SD & $9.20 \pm 3.329$ & $7.11 \pm 4.035$ & $2.52 \pm 3.135$ & 35.583 & 0.000 \\
\hline MMSE, mean \pm SD & $25.17 \pm 5.805$ & $24.50 \pm 3.400$ & $12.94 \pm 6.557$ & 75.148 & 0.000 \\
\hline MoCA, mean \pm SD & $20.74 \pm 5.674$ & $18.74 \pm 4.507$ & $8.58 \pm 5.038$ & 68.758 & 0.000 \\
\hline $\mathrm{SBP}(\mathrm{mmHg})$, mean $\pm \mathrm{SD}$ & $123.87 \pm 13.643$ & $128.34 \pm 12.457$ & $127.84 \pm 1 \mid .198$ & 2.373 & 0.096 \\
\hline $\mathrm{DBP}(\mathrm{mmHg})$, mean $\pm \mathrm{SD}$ & $76.27 \pm 8.669$ & $77.5 I \pm 9.479$ & $77.76 \pm 6.340$ & 0.463 & 0.630 \\
\hline Height $(\mathrm{cm})$, mean $\pm S D$ & $1.60 \pm 0.076$ & $\mathrm{I} .6 \mathrm{I} \pm 0.076$ & $1.563 \pm 0.085$ & 3.456 & 0.034 \\
\hline Weight $(\mathrm{kg})$, mean $\pm \mathrm{SD}$ & $60.59 \pm 9.745$ & $64.44 \pm 11.282$ & $56.07 \pm 13.703$ & 6.195 & 0.003 \\
\hline BMI $\left(\mathrm{kg} / \mathrm{m}^{2}\right)$, mean $\pm \mathrm{SD}$ & $23.78 \pm 3.186$ & $24.91 \pm 4.319$ & $22.98 \pm 4.099$ & 2.956 & 0.055 \\
\hline
\end{tabular}

Abbreviations: BMI, body mass index; DBP, diastolic blood pressure; MCl, mild cognitive impairment; MMSE, Mini-Mental State Examination; MoCA, Montreal Cognitive Assessment; SBP, systolic blood pressure.

Table 4 The detailed disease information among the three groups

\begin{tabular}{|c|c|c|c|c|c|}
\hline Groups & Normal $(n=82)$ & $\mathrm{MCl}(\mathrm{n}=82)$ & $A D(n=33)$ & $\boldsymbol{F}$ & $P$-value \\
\hline \multicolumn{6}{|l|}{ Diabetes, n (\%) } \\
\hline Yes & $10(5.1)$ & $20(10.2)$ & $3(1.5)$ & 3.514 & 0.032 \\
\hline No & $72(36.5)$ & $62(31.5)$ & $30(15.2)$ & & \\
\hline \multicolumn{6}{|l|}{ Drug therapy for diabetes, $\mathrm{n}(\%)$} \\
\hline Yes & $9(28.1)$ & $16(50.0)$ & $2(6.3)$ & 0.420 & 0.661 \\
\hline No & I (3.I) & $4(12.5)$ & I (3.I) & & \\
\hline Diabetes duration (mean $\pm \mathrm{SD}$ ) & $10.20 \pm 9.485$ & $9.30 \pm 6.208$ & $8.67 \pm 7.095$ & 0.071 & 0.932 \\
\hline \multicolumn{6}{|l|}{ Hyperlipidemia, n (\%) } \\
\hline Yes & $15(7.6)$ & $25(12.7)$ & I (0.5) & 13.272 & 0.001 \\
\hline No & $67(34)$ & $57(28.9)$ & $32(16.2)$ & & \\
\hline \multicolumn{6}{|l|}{ Drug therapy for hyperlipidemia, $\mathrm{n}(\%)$} \\
\hline Yes & $7(20.6)$ & II (32.4) & $0(0)$ & 0.747 & 0.477 \\
\hline No & $4(11.8)$ & $12(35.3)$ & $0(0)$ & & \\
\hline Hyperlipidemia duration (mean \pm SD) & $9.59 \pm 8.864$ & $7.342 \pm 8.890$ & & 0.567 & 0.573 \\
\hline \multicolumn{6}{|l|}{ History of traumatic brain injury, $n(\%)$} \\
\hline Yes & $4(2.0)$ & $10(5.1)$ & $0(0)$ & 3.235 & 0.041 \\
\hline No & $78(39.6)$ & $72(36.5)$ & $33(16.8)$ & & \\
\hline \multicolumn{6}{|l|}{ Family history of dementia, $\mathrm{n}(\%)$} \\
\hline Yes & $\mathrm{I}(0.5)$ & $3(1.5)$ & $0(0)$ & 2.451 & 0.653 \\
\hline No & $80(40.8)$ & $79(40.3)$ & $33(16.8)$ & & \\
\hline
\end{tabular}

Notes: Results are in response to a one-way ANOVA, and $P<0.05$ was considered statistically significant.

Abbreviations: $A D$, Alzheimer's disease; $\mathrm{MCl}$, mild cognitive impairment. 
Table 5 The comparison of detailed disease information between $\mathrm{MCl}$ group and AD group

\begin{tabular}{|c|c|c|c|c|}
\hline Groups & $\mathrm{MCl}$ & AD & $\chi^{2}$ or $t$ & $P$-value \\
\hline \multicolumn{5}{|l|}{ Diabetes, n (\%) } \\
\hline Yes & $20(17.4)$ & $3(2.6)$ & 3.442 & 0.075 \\
\hline No & $62(53.9)$ & $30(26.1)$ & & \\
\hline Diabetes duration (mean $\pm S D$ ) & $9.30 \pm 6.208$ & $8.67 \pm 7.095$ & 0.146 & 0.895 \\
\hline \multicolumn{5}{|l|}{ Hyperlipidemia, n (\%) } \\
\hline Yes & $25(21.7)$ & $\mathrm{I}(0.9)$ & 10.139 & $0.00 I^{*}$ \\
\hline No & $57(49.6)$ & $32(27.8)$ & & \\
\hline \multicolumn{5}{|c|}{ History of traumatic brain injury, $\mathrm{n}(\%)$} \\
\hline Yes & $10(8.7)$ & $0(0.0)$ & 4.408 & 0.060 \\
\hline No & $72(62.6)$ & $33(16.8)$ & & \\
\hline \multicolumn{5}{|l|}{ Family history of dementia, n (\%) } \\
\hline Yes & $3(2.6)$ & $0(0.0)$ & 1.668 & 0.434 \\
\hline No & $78(67.8)$ & $33(16.8)$ & & \\
\hline
\end{tabular}

Note: $* P<0.05$.

Abbreviations: $\mathrm{AD}$, Alzheimer's disease; $\mathrm{MCl}$, mild cognitive impairment.

\section{Discussion}

In this study, T2DM was shown to be a risk factor for elderly Chinese people with MCI progressing into $\mathrm{AD}$ (we had adjusted those possible related factors, such as age and education), while it had no impact on the normal population. Leibson et $\mathrm{al}^{21}$ confirmed that individuals with T2DM had increased the risk for developing AD. In a longitudinal cohort study lasting up to 9 years, the risk of developing $\mathrm{AD}$ was $65 \%$ higher in persons with diabetes than in nondiabetic controls. ${ }^{22}$ Huang et $\mathrm{al}^{23}$ found that over a maximum 11 years of follow-up, diabetic patients experienced a higher incidence of $\mathrm{AD}$ than nondiabetic subjects $(0.48 \%$ vs $0.37 \%$ ) but other studies have not shown a link between T2DM and dementia. ${ }^{21,24}$ Although the association between T2DM and these modest changes in cognition is now well established, the relation between T2DM and MCI is still an area of controversy. ${ }^{25}$

In addition, we did not find the effect of the duration of T2DM and hypoglycemic agents on cognitive function. However, previous studies had shown that the duration of T2DM was negatively correlated with cognitive function. ${ }^{26} \mathrm{Hsu}$ et a ${ }^{27}$ pointed out that both sulfonylureas and metformin could decrease the risk of dementia, and a combined use of these two drugs could decrease the risk of dementia in T2DM patients by

Table 6 The factor that might be associated with cognition

\begin{tabular}{llllllll}
\hline Factor & $B$ & SE & Wald & of & $P$-value & OR & $95 \%$ \\
\hline
\end{tabular}

\begin{tabular}{llllllll}
\hline T2DM & 3.906 & 1.597 & 5.982 & I & 0.014 & 49.723 & $21.173-111.98$ \\
\hline
\end{tabular}

Notes: Results are in response to logistic regression analysis and $P<0.05$ is considered statistically significant.

Abbreviations: $\mathrm{df}$, degrees of freedom; OR, odds ratio; SE, standard error; T2DM, type 2 diabetes mellitus; $\mathrm{Cl}$, confidence interval.
$35 \%$ for $>8$ years. In addition, Abbatecola et $\mathrm{a}^{28}$ proved that rosiglitazone may protect against cognitive decline in older individuals with T2DM and MCI. However, Ma et al ${ }^{29}$ thought that insulin was not associated with significantly changed risk. And, in the Rotterdam study, the results showed that patients treated with insulin were at a 4.3 -fold higher relative risk of dementia. ${ }^{30}$ So, the results of our study are not very consistent with the previous conclusions, and this might be the result of insufficient sample size or sample selection bias.

There are several explanations for why T2DM might promote the conversion of MCI to AD. First, T2DM is associated with obesity, hypertension, inflammation, dyslipidemia, and hypothalamic pituitary adrenocortical axis abnormalities, all of which have been shown to negatively impact the brain. ${ }^{31}$ In our study, we found that patients with MCI had higher incidence of hyperlipidemia than AD controls (Table 5). Previous studies suggested that hyperlipidemia would increase the risk of $\mathrm{VD}$ and $\mathrm{AD},{ }^{32}$ so $\mathrm{T} 2 \mathrm{DM}$ might promote the progression of transforming MCI into $\mathrm{AD}$, by affecting the lipid metabolism. Second, individuals with T2DM were more likely to lead to the hyperphosphorylation of tau protein, abnormal regulation in the clearance process of amyloid beta, higher levels of cortical IL-6, and high frequency of microvascular infarcts. ${ }^{33,34}$ Third, impaired insulin-PI3K-AKT signaling is one of the characteristics of T2DM, which might contribute to neurodegeneration in $\mathrm{AD}$ by downregulation of O-linked attachment of the monosaccharide $\beta$ - $\mathrm{N}$-acetyl-glucosamine (O-GlcNAcylation) and the consequent promotion of abnormal tau hyperphosphorylation and neurodegeneration. ${ }^{35}$

\section{Conclusion}

T2DM might be a risk factor for MCI progressing into AD. 


\section{Limitations}

There are some limitations in this study. First, the sample size was limited. Second, we only collected the information on whether the subjects had T2DM but we did not collect the information about detailed medication. In other words, the data on use of drugs to control T2DM were incomplete. Third, this was only a cross-sectional study, we could not determine the long-term influence of T2DM on cognitive function.

\section{Acknowledgment}

This work was supported by a grant from the China Ministry of Science and Technology (2009BAI77B03).

\section{Disclosure}

The authors report no conflicts of interest in this work.

\section{References}

1. Ren RJ, Zhang YF, Dammer EB, et al. Peripheral blood MicroRNA expression profiles in Alzheimer's disease: screening, validation, association with clinical phenotype and implications for molecular mechanism. Mol Neurobiol. Epub 2015 Oct 26.

2. Sarlus H, Eyjolfsdottir H, Eriksdotter M, Oprica M, Schultzberg M. Influence of allergy on immunoglobulins and amyloid-beta in the cerebrospinal fluid of patients with Alzheimer's disease. J Alzheimers Dis. 2015;48(2):495-505.

3. Korolev IO, Symonds LL, Bozoki AC. Predicting progression from mild cognitive impairment to Alzheimer's dementia using clinical, MRI, and plasma biomarkers via probabilistic pattern classification. PLoS One. 2016;11(2):e0138866.

4. Mitchell AJ, Shiri-Feshki M. Rate of progression of mild cognitive impairment to dementia - meta-analysis of 41 robust inception cohort studies. Acta Psychiatr Scand. 2009;119(4):252-265.

5. Koran ME, Wagener M, Hohman TJ. Sex differences in the association between $\mathrm{AD}$ biomarkers and cognitive decline. Brain Imaging Behav. Epub 2016 Feb 3.

6. Knight EM, Ruiz HH, Kim SH, et al. Unexpected partial correction of metabolic and behavioral phenotypes of Alzheimer's APP/PSEN1 mice by gene targeting of diabetes/Alzheimer's-related Sorcs1. Acta Neuropathol Commun. 2016;4:16.

7. Awad N, Gagnon M, Messier C. The relationship between impaired glucose tolerance, type 2 diabetes, and cognitive function. J Clin Exp Neuropsychol. 2004;26(8):1044-1080.

8. Kopf D, Frolich L. Risk of incident Alzheimer's disease in diabetic patients: a systematic review of prospective trials. $J$ Alzheimers Dis. 2009;16(4):677-685.

9. Sims-Robinson C, Kim B, Rosko A, Feldman EL. How does diabetes accelerate Alzheimer disease pathology? Nat Rev Neurol. 2010;6(10): $551-559$.

10. Ng TP, Feng L, Nyunt MS, et al. Metabolic syndrome and the risk of mild cognitive impairment and progression to dementia: follow-up of the Singapore longitudinal ageing study cohort. JAMA Neurol. 2016; 73(4):456-463.

11. Leibson CL, Rocca WA, Hanson VA, et al. The risk of dementia among persons with diabetes mellitus: a population-based cohort study. Ann N Y Acad Sci. 1997;826:422-427.

12. Mittal K, Katare DP. Shared links between type 2 diabetes mellitus and Alzheimer's disease: a review. Diabetes Metab Syndr. Epub 2016 Feb 11.

13. Sebastiao I, Candeias E, Santos MS, de Oliveira CR, Moreira PI, Duarte AI. Insulin as a bridge between type 2 diabetes and Alzheimer disease - how anti-diabetics could be a solution for dementia. Front Endocrinol. 2014;5:110.
14. O'Bryant SE, Humphreys JD, Smith GE, et al. Detecting dementia with the Mini-Mental State Examination in highly educated individuals. Arch Neurol. 2008;65(7):963-967.

15. Piccinin AM, Muniz-Terrera G, Clouston S, et al. Coordinated analysis of age, sex, and education effects on change in MMSE scores. J Gerontol B Psychol Sci Soc Sci. 2013;68(3):374-390.

16. Trzepacz PT, Hochstetler H, Wang S, Walker B, Saykin AJ. Relationship between the Montreal Cognitive Assessment and Mini-mental State Examination for assessment of mild cognitive impairment in older adults. BMC Geriatr. 2015;15:107.

17. Tiffin-Richards FE, Costa AS, Holschbach B, et al. The Montreal Cognitive Assessment (MoCA) - a sensitive screening instrument for detecting cognitive impairment in chronic hemodialysis patients. PLoS One. 2014;9(10):e106700.

18. Petersen RC, Smith GE, Waring SC, Ivnik RJ, Tangalos EG, Kokmen E. Mild cognitive impairment: clinical characterization and outcome. Arch Neurol. 1999;56(3):303-308.

19. Petersen RC. Mild cognitive impairment as a diagnostic entity. J Intern Med. 2004;256(3):183-194.

20. Almeida OP, Almeida SA. [Reliability of the Brazilian version of the ++abbreviated form of Geriatric Depression Scale (GDS) short form]. Arq Neuropsiquiatr. 1999;57(2b):421-426.

21. Leibson CL, Rocca WA, Hanson VA, et al. Risk of dementia among persons with diabetes mellitus: a population-based cohort study. Am J Epidemiol. 1997;145(4):301-308.

22. Arvanitakis Z, Wilson RS, Bienias JL, Evans DA, Bennett DA. Diabetes mellitus and risk of Alzheimer disease and decline in cognitive function. Arch Neurol. 2004;61(5):661-666.

23. Huang CC, Chung CM, Leu HB, et al. Diabetes mellitus and the risk of Alzheimer's disease: a nationwide population-based study. PLoS One. 2014;9(1):e87095.

24. Xu WL, Qiu CX, Wahlin A, Winblad B, Fratiglioni L. Diabetes mellitus and risk of dementia in the Kungsholmen project: a 6-year follow-up study. Neurology. 2004;63(7):1181-1186.

25. Biessels GJ, Staekenborg S, Brunner E, Brayne C, Scheltens P. Risk of dementia in diabetes mellitus: a systematic review. Lancet Neurol. 2006; 5(1):64-74.

26. Hassing LB, Grant MD, Hofer SM, et al. Type 2 diabetes mellitus contributes to cognitive decline in old age: a longitudinal populationbased study. J Int Neuropsychol Soc. 2004;10(4):599-607.

27. Hsu CC, Wahlqvist ML, Lee MS, Tsai HN. Incidence of dementia is increased in type 2 diabetes and reduced by the use of sulfonylureas and metformin. J Alzheimers Dis. 2011;24(3):485-493.

28. Abbatecola AM, Lattanzio F, Molinari AM, et al. Rosiglitazone and cognitive stability in older individuals with type 2 diabetes and mild cognitive impairment. Diabetes Care. 2010;33(8):1706-1711.

29. Ma F, Wu T, Miao R, Xiao YY, Zhang W, Huang G. Conversion of mild cognitive impairment to dementia among subjects with diabetes: a population-based study of incidence and risk factors with five years of follow-up. J Alzheimers Dis. 2015;43(4):1441-1449.

30. Ott A, Stolk RP, van Harskamp F, Pols HA, Hofman A, Breteler MM. Diabetes mellitus and the risk of dementia: the Rotterdam Study. Neurology. 1999;53(9):1937-1942.

31. Bruehl H, Wolf OT, Sweat V, Tirsi A, Richardson S, Convit A. Modifiers of cognitive function and brain structure in middle-aged and elderly individuals with type 2 diabetes mellitus. Brain Res. 2009; 1280:186-194.

32. Panpalli Ates M, Karaman Y, Guntekin S, Ergun MA. Analysis of genetics and risk factors of Alzheimer's disease. Neuroscience. 2016;325: 124-131.

33. Freude S, Plum L, Schnitker J, et al. Peripheral hyperinsulinemia promotes tau phosphorylation in vivo. Diabetes. 2005;54(12):3343-3348.

34. Kulstad JJ, Green PS, Cook DG, et al. Differential modulation of plasma beta-amyloid by insulin in patients with Alzheimer disease. Neurology. 2006;66(10):1506-1510.

35. Liu Y, Liu F, Grundke-Iqbal I, Iqbal K, Gong CX. Deficient brain insulin signalling pathway in Alzheimer's disease and diabetes. J Pathol. 2011;225(1):54-62. 


\section{Publish your work in this journal}

Neuropsychiatric Disease and Treatment is an international, peerreviewed journal of clinical therapeutics and pharmacology focusing on concise rapid reporting of clinical or pre-clinical studies on a range of neuropsychiatric and neurological disorders. This journal is indexed on PubMed Central, the 'PsycINFO' database and CAS, and is the official journal of The International Neuropsychiatric Association (INA). The manuscript management system is completely online and includes a very quick and fair peer-review system, which is all easy to use. Visit http://www.dovepress.com/testimonials.php to read real quotes from published authors.

Submit your manuscript here: http://www.dovepress.com/neuropsychiatric-disease-and-treatment-journal 